\title{
BLOOD-CEREBROSPINAL FLUID BROMIDE RATIOS IN MENTAL PATIENTS
}

\author{
BY \\ A. J. COPPEN \\ From the Institute of Psychiatry, Maudsley Hospital, London
}

\begin{abstract}
"The fixity of the internal environment is in short the condition of mental activity." Barcroft (1934), by this modification of Claude Bernard's famous aphorism, emphasized the necessity of maintaining the constancy of the composition of the brain to ensure its normal functioning. Among the mechanisms for ensuring this constancy are the blood-brain and blood-cerebrospinal fluid barriers.

The term "blood-C.S.F. barrier" was first used by Stern (1923) and the concept was based on observations that the concentration of numerous substances in the blood and in the cerebrospinal fluid differed in such a way as to suggest a "barrier" between the two fluids. Many substances were used in studies of this barrier, notably sodium bromide whose many advantages were pointed out by Walter (1925). He found the ratio between the concentration of bromide in the cerebrospinal fluid and the concentration of bromide in the serum to be about constant, for any particular patient, when a steady state had been achieved.
\end{abstract}

The publication of Walter's observations was followed by the widespread use of bromide in the investigation of neurological and psychiatric disorders. The chief findings in the latter may be summarized as follows. Whereas the bromide ratio was normal in patients suffering from manicdepressive psychosis, schizophrenics had ratios indicating decreased permeability and patients with certain organic psychoses had ratios indicating increased permeability. There was considerable overlap between the ratios for the different groups, and the evaluation of the results remained equivocal because of the various criticisms which were levelled at the accuracy of the technique (e.g., FremontSmith, Dailey, and Sloan, 1935; Carmichael, Rheingold, and Linder, 1935). It was thus desirable to repeat the work with a more accurate method. Such a method was provided by Hunter (1953).

The purpose of the present investigation was to see if mental diseases are associated with an alteration in the bromide ratio determined by Hunter's method.

\section{Material and Methods}

The diagnostic groups studied were: (a) Schizophrenia, (b) affective disorders, $(c)$ senile psychosis, $(d)$ puerperal psychosis, $(e)$ general paresis. Altogether 79 patients were tested.

The ratios obtained from the patients were compared statistically with a control group. In a test involving a lumbar puncture it is hardly possible to obtain a random sample of healthy members of the general population. However, Drs. Honor Smith and George Hunter generously provided the clinical details and bromide ratios of 34 patients suffering from somatic complaints, in whom there was no evidence of mental illness or disease of the central nervous system. These patients formed the control group of the present investigation and will be described in detail later. The psychiatric subjects were patients in whom the diagnosis was unequivocal and had been confirmed by at least one consultant psychiatrist. To avoid the possible effects of deep insulin and electroconvulsive therapy on the bromide ratio, no patient was included who had had physical treatment during the year preceding the test.

Sodium bromide was administered orally for three days in a dose of $1 \mathrm{~g}$. thrice daily. Two days were then allowed to elapse and on the sixth day cerebrospinal fluid was obtained by lumbar puncture with the patient lying in the right lateral position. Approximately $5 \mathrm{ml}$. of fluid was obtained by direct flow into a chemically clean container. About $10 \mathrm{ml}$. of blood was obtained by venepuncture within $\mathbf{3 0}$ minutes of the lumbar puncture. The blood was allowed to clot and was centrifuged to separate cells and serum.

The reliability of the bromide estimations was investigated by calculating the product moment correlation coefficient between the duplicate results of the first 20 estimations. The correlation coefficient was high (0.98) indicating a very satisfactory level of reliability for the test both in blood and cerebrospinal fluid.

\section{Results}

The mean and standard deviation of the bromide ratio and the age of the patients of the control and the other groups are given in Table 1. Comparisons of the bromide ratios between the various groups by the $t$ test are shown in Table II. 
TABLE I

BROMIDE RATIOS AND AGES OF THE CONTROL AND PSYCHIATRIC GROUPS

\begin{tabular}{|c|c|c|c|c|c|c|}
\hline \multirow{2}{*}{ Group } & \multirow{2}{*}{ No. } & \multicolumn{2}{|c|}{ Age } & \multicolumn{2}{|c|}{ Bromide Ratio } & \multirow{2}{*}{$\begin{array}{l}\text { Correlation Coefficient for } \\
\text { Age and Bromide Ratio }\end{array}$} \\
\hline & & Mean & S.D. & Mean & S.D. & \\
\hline $\begin{array}{l}\text { Control } \\
\text { Schizophrenia } \\
\text { Affective disorders } \\
\text { Senile dementia } \\
\text { Puerperal psychosis } \\
\text { General paresis }\end{array}$ & $\begin{array}{r}34 \\
27 \\
17 \\
17 \\
10 \\
8\end{array}$ & $\begin{array}{l}42 \cdot 7 \\
31 \cdot 4 \\
40 \cdot 9 \\
72 \cdot 6 \\
29 \cdot 7 \\
56 \cdot 0\end{array}$ & $\begin{array}{r}20 \cdot 2 \\
7 \cdot 8 \\
11 \cdot 3 \\
3 \cdot 4 \\
3 \cdot 0 \\
14 \cdot 2\end{array}$ & $\begin{array}{l}0 \cdot 39 \\
0 \cdot 40 \\
0 \cdot 39 \\
0 \cdot 42 \\
0 \cdot 38 \\
0 \cdot 37\end{array}$ & $\begin{array}{l}0.06 \\
0.07 \\
0.05 \\
0.06 \\
0.06 \\
0.03\end{array}$ & $\begin{array}{l}0.41 \text { P }<0.02 \\
0.10 \text { not significant } \\
0.55 \text { P } 0.05 \\
0.28 \text { not significant } \\
0.49 \text { not significant } \\
0.54 \text { not significant }\end{array}$ \\
\hline
\end{tabular}

TABLE II

COMPARISON OF BROMIDE RATIOS OF VARIOUS PSYCHIATRIC GROUPS WITH CONTROL GROUP AND EACH OTHER BY $t$ TEST

\begin{tabular}{l|l|l}
\hline \multicolumn{1}{c|}{ Groups Compared } & $\mathrm{t}$ & $\mathrm{P}$ \\
\hline Schizophrenia: control & $\mathbf{0 . 4 4}$ & Not significant \\
Schizophrenia : affective disorder & $\mathbf{0 . 3 6}$ & Not significant \\
Schizophrenia: senile psychosis & 1.13 & Not significant \\
Affective disorder: control & 0 & Not significant \\
Affective disorder: senile psychosis & 1.55 & Not significant \\
Senile psychosis: control & 1.79 & Not significant \\
Puerperal psychosis: control & $\mathbf{0 . 3 0}$ & Not significant \\
Puerperal psychosis: schizophrenia & 0.57 & Not significant \\
General paresis: control & 0.95 & Not significant \\
General paresis: senile psychosis & $\mathbf{2 . 2 3}$ & $\mathbf{0 . 0 5}$ \\
\hline
\end{tabular}

Control Group.-This consisted of 34 patients with the following diagnosis, the number of patients in each category being given in brackets: $(a)$ Glaucoma (6); (b) tuberculosis without meningitis (11); (c) pain referred to various parts of the body, namely, the face (2), the head (8), the arm (2), and the leg $(1) ;(d)$ myxoedema (4).

Schizophrenia.-Some of the patients tested had had schizophrenia for many years, in others the illness was of recent onset. The bromide ratios of the latter were substantially the same as those of the chronic patients. The group consisted of 27 patients, 18 of whom were hebephrenic, three catatonic, five showed simple schizophrenia, and one paranoid schizophrenia.

Affective Disorders. - This group consisted of 17 patients suffering from depression.

Senile Dementia.-There were 17 in this group. Patients with evidence of cerebral arterial disease, such as cerebrovascular lesions, hypertension, and a markedly fluctuating or remitting course were excluded.

Puerperal Psychosis.-This group consisted of 10 women who became severely mentally disturbed in the course of their puerperium. Nine of them presented a schizophrenic-like picture, one presented with depressive features. They were tested within one month of the onset of symptoms.

General Paresis.-This group consisted of seven patients with treated general paresis and one with juvenile paresis in whom there were residual mental symptoms necessitating a continued stay in hospital. The diagnosis had been established in every case by serological and cerebrospinal fluid investigations.

There was no significant difference between the bromide ratios of the psychiatric groups when compared with each other or with the controls except in the case of patients with general paresis, who had lowered bromide ratios. A positive correlation was found between age and bromide ratio in the controls and in patients with affective disorders.

\section{Discussion and Conclusions}

The results of this investigation indicate that, with the exception of the general paresis group, none of the psychiatric patients had bromide ratios that differed significantly from the control group.

The discrepancy between these results and those of previous workers is not easily explained. It cannot be entirely accounted for by inaccuracies in theif technique of estimating bromide. A more importan source of error would be that they performed thetest on the day following the administration of bromide. As Hunter, Smith, and Taylor (1954) showed, this is too short a time for the steady state to be reached. It is therefore possible that the difference they reported between the groups of mental patients is related to an abnormal rate of penetration of bromide into the cerebrospinal fluid rather than to an abnormal steady state distribution. Rates of penetration of bromide have not been systematically measured in mental patients, but there is some evidence that the reverse process, i.e., the penetration of sodium iodide from the cerebrospinal fluid into the blood is abnormal in schizophrenics. This was found by Guttmann (1929). He used Foerster's (1925) test, in which $2 \mathrm{ml}$. of $10 \%$ solution of sodium iodide is injected into the lumbar subarachnoid space and the excretion of iodide is studied in the urine; in normal conditions the iodide appears in the urine within 30 to 45 minutes of the injection, and the duration of iodide excretion is regarded as normal up to 35 hours from its injection into the cerebrospinal fluid. In 50 schizophrenics Guttmann found that 36 showed a delayed excretion of up to seven hours and 14 an abnormally long duration of iodide 
excretion; only nine showed a normal iodide excretion.

The low bromide ratio observed in the general paretic group is also difficult to account for in contrast to the increased permeability found by earlier workers, except that this was with untreated cases. Kral (1928) and Malamud and Wilson (1929) reported that patients who had been given malaria therapy and improved showed a change from increased to normal permeability.

The control group and the group of affective disorders show a significant positive correlation between age and bromide ratio, and this confirms similar findings by Büchler (1926), Carmichael et al. (1935), and Bourdillon, Fischer-Williams, Smith, and Taylor (1957). In contrast to these two groups, the bromide ratios of the schizophrenic patients do not show a correlation with age. The small numbers and limited age range of the groups of senile dementia, puerperal psychosis, and general paresis are probably a sufficient reason why a positive correlation between age and bromide ratio did not emerge from these groups.

The present work shows that the steady-state bromide ratio is unchanged in mental patients, but it would be rash to conclude from this that the bloodbrain and blood-cerebrospinal fluid barriers are normal in these patients. As Davson (1956) demonstrated, permeability is best measured by determining the rate of penetration of a substance from one side of a membrance to another, rather than by measuring the steady-state ratio. Thus Bourdillon et al. (1957) found a decreased rate of penetration of bromide and sodium into the cerebrospinal fluid in patients with extrapyramidal lesions, although the steady-state ratios of these substances were normal.

\section{Summary}

An accurate method of determining the bromide content of serum and cerebrospinal fluid was applied to a study of the permeability of the blood cerebrospinal fluid barrier in mental patients. The diagnostic groups investigated were $(a)$ schizophrenia, $(b)$ affective disorders, $(c)$ senile dementia, $(d)$ puerperal psychosis, $(e)$ general paresis, and the findings were compared with those in a control group of patients without any mental disorder or disease of the central nervous system. The bromide ratios in schizophrenia, senile dementia, affective disorders, and puerperal psychosis do not differ from those in patients not suffering from mental illness. Patients suffering from general paresis had a slightly decreased bromide ratio.

I should like to thank Dr. Honor Smith and Dr. George Hunter for generously providing the bromide ratios of the control group.

\section{REFERENCES}

Barcroft, J. (1934). Features in th? Architecture of Physiologica Function. Cambridge University Press, London.

Bourdillon, R. B., Fischer-Williams, M., Smith, Honor V., and Taylor, K. B. (1957). J. Neurol.' Neurosurg. Psychiat., 20, 79.

Büchler, P. (1926). Arch. Psychiat and Nervenkr., 77, 613.

Carmichael, H. T., Rheingold, J. C., and Linder, F. E. (1935). J. nerv. ment. Dis., 82, 125.

Davson, H. (1956). Physiology of the Ocular and Cerebrospinal Fluids. J. \& A. Churchill, London.

Foerster, O. (1925). Z. ges. Neurol. Psychiat., 94, 512.

Fremont-Smith, F., Dailey, M. E., and Sloan, D. H. (1935). Arch. Neurol. Psychiat. (Chicago), 33, 764.

Guttmann, L. (1929). Arch. Psychiat. Nervenkr., 88, 211.

Hunter, G. (1953). Biochem. J., 54, 42

- , Smith, H. V., and Taylor, L. M. (1954). Ibid., 56, 588.

Kral, A. (1928). Z. ges. Neurol. Psychiat. 115, 158. (Chicago), 22, 1135.

Stern, L. (1923). Schweiz. med. Wschr., 4, 792.

Walter, F. K. (1925). Z. ges. Neurol. Psychiat., 95, 522. 